\title{
The Molecular Links of Re-Emerging Therapy: A Review of Evidence of Brahmi (Bacopa monniera)
}

\author{
Deepali Mathur ${ }^{1}$, Kritika Goyal $^{2}$, Veena Koul ${ }^{3}$ and Akshay Anand ${ }^{2 *}$ \\ ${ }^{1}$ Department of Functional Biology, Faculty of Biological Sciences, University of Valencia, Valencia, Spain, ${ }^{2}$ Neuroscience \\ Research Lab, Department of Neurology, Post Graduate Institute of Medical Education and Research, Chandigarh, India, \\ ${ }^{3}$ Center for Biomedical Engineering, Indian Institute of Technology, New Delhi, India
}

OPEN ACCESS

Edited by:

Xiaohui Fan,

Zhejiang University, China

Reviewed by:

Pinarosa Avato,

Università degli Studi di Bari Aldo

Moro, Italy

Manoj Gajanan Kulkarni,

University of KwaZulu-Natal,

South Africa

${ }^{*}$ Correspondence:

Akshay Anand

akshay2anand@gmail.com

Specialty section:

This article was submitted to

Ethnopharmacology,

a section of the journal

Frontiers in Pharmacology

Received: 22 October 2015

Accepted: 16 February 2016

Published: 04 March 2016

Citation:

Mathur D, Goyal K, Koul V and Anand A (2016) The Molecular Links of Re-Emerging Therapy: A Review of

Evidence of Brahmi (Bacopa monniera). Front. Pharmacol. 7:44.

doi: 10.3389/fphar.2016.00044
The convolution associated with memory is being resolved with advancement in neuroscience. According to the concurrent assumptions, synaptic plasticity forms one of the basis of memory formation, stabilization and strengthening. In Alzheimer's disease (AD), which is generally characterized by memory dysfunction, connections amongst the cells in the brain are attenuated or lost leading to degeneration of neural networks. Numerous attempts have been made to find new therapies for memory dysfunction with increasing attention and investments being laid on herbal drugs. Many herbal plants and extracts have already documented beneficial results when tested for antiamnesic effects. Brahmi (Bacopa monniera) is one such common herbal drug, which is employed for a long time in the Indian and Chinese medical system in order to treat several disorders. Previous research has shown that Brahmi exerts many pharmacological effects including memory boosting capacity in the treatment of Alzheimer's disease and Schizophrenia, exhibiting antiparkinsonian, antistroke, and anticonvulsant potentials. The present review discusses the chemical constituents of Brahmi along with in vitro and in vivo studies based on the pharmacological effects exerted by it. The efficacy of Brahmi in treating various disorders has evoked sufficient research in recent years and now it is a time to launch multiple clinical trials.

Keywords: Brahmi, pharmacological effects, anti-parkinson, anti-convulsant, anti-depressant, clinical trials

\section{INTRODUCTION}

The significance of Brahmi (Bacopa monniera Linn.) in improving memory and learning skills was first published in 1982 (Singh and Dhawan, 1982). Since then various studies have been conducted in animals to determine various properties exhibited by the medicinal herb. The potential of Brahmi in shielding neuronal structure and/or function has also been evaluated in a number of growing studies. Brahmi is a well-known Ayurvedic medicinal herb, which is re-emerging as a recourse to treatment of memory related disorders. Its medicinal potency is reported both in Indian as well as Chinese traditional literature. Although many chemical compounds have been isolated from Brahmi, the active fractions of this medicinal plant contain bacoside- $\mathrm{A}$ and bacoside-B. A number of other phytochemicals such as alkaloids, glycosides, flavonoids, saponins etc. are the constituents of Brahmi (Dutta and Basu, 1963; Chatterji et al., 1965; Basu et al., 1967).

Investigations conducted so far have revealed that Brahmi exerts many pharmacological effects (Figure 1) including memory boosting effect in the treatment of Alzheimer Disease and 
Schizophrenia, besides displaying antiparkinson, antistroke, and anticonvulsant potentials. The present review discusses the chemical constituents of Brahmi together with in vitro and in vivo studies based on its molecular and pharmacological effects (Figure 1).

\section{CHEMICAL CONSTITUENTS OF BRAHMI}

Bacopa monniera is characterized by its typical chemical composition which predominantly includes compounds like dammarane-type triterpenoid saponins called as bacosides, with jujubogenin or pseudo-jujubogenin moieties as their aglycone units. Based on the structural similarity, 12 analogs from the family of Bacosides have been elucidated. In the recent past, bacopasides I-XII, a different class of saponins have been identified as an important constituent of the herbal extract (Rauf et al., 2013). Apart from hersaponin, apigenin, D-mannitol, monnierasides I-III, plantainoside B and cucurbitacin; the alkaloids brahmine, herpestine and nicotine have also been classified in the chemical constituents of Bacopa monniera. Bacoside $\mathrm{A}$ is the most studied and potent constituent of Bacopa, which is composed of bacoside A3, bacopasaponin C, bacopaside II and bacopaside X (Srivastava et al., 2012; Deepak and Amit, 2013; Singh et al., 2014; Figure 2).

Various research groups have separated the constituents of Brahmi through HPLC. Several mobile phase systems have been used for the purpose of separating various chemical constituents of Brahmi like methanol and water (Ganzera et al., 2004); mixture of acetonitrile and $0.05 \mathrm{M}$ sodium sulfate $(\mathrm{pH} 2.3 ; 68.5: 31.5$; Sivaramakrishna et al., 2005; Murthy et al., 2006); $0.25 \%$ orthophosphoric acid in water and acetonitrile (Phrompittayarat et al., 2007; Sumathi and Devaraj, 2009); but till now no

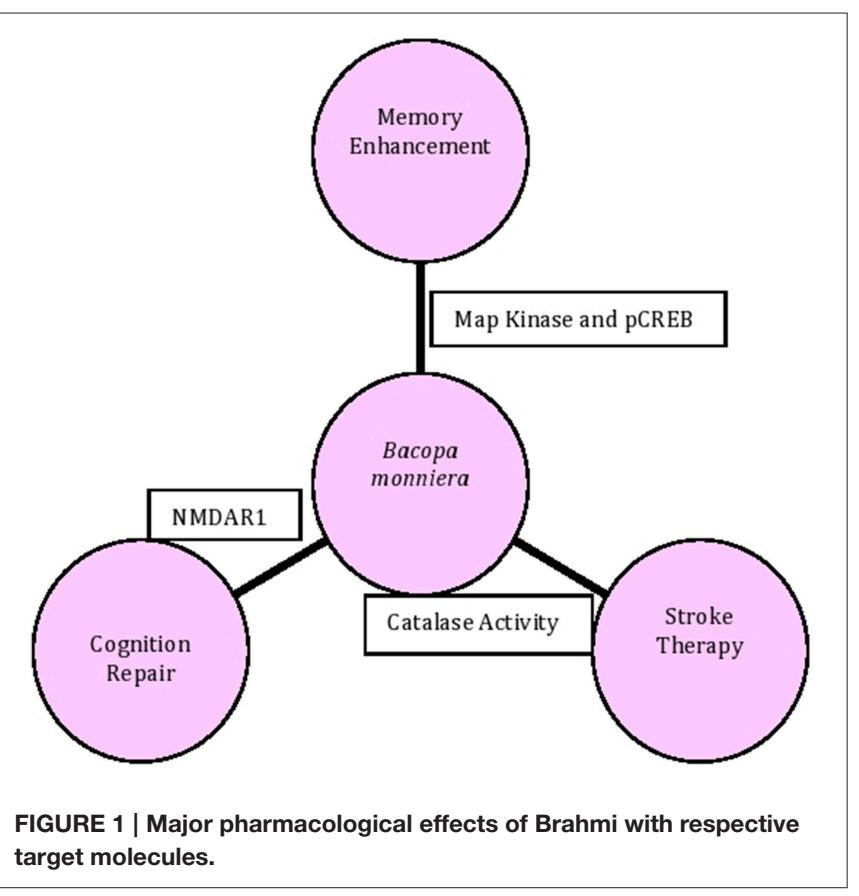

consensus mobile phase system has come up for the analysis of Brahmi constituents.

\section{ACTIVE COMPONENTS}

The therapeutic effects of Bacopa monniera are believed to be exerted through triterpenoid saponins present in the plant extract. Bacosides are the triterpenoid saponins of prime importance. They have been shown to enhance nerve impulse transmission. The bacosides promote the repair of damaged neurons by upregulating neuronal synthesis and kinase activity. The bacosides also aid in the restoration of synaptic activity, which ultimately leads to nerve impulse transmission (Singh and Dhawan, 1997). The nerve impulse transmission, plays a vital role in promoting healthy cognitive functions like attention span, focus, concentration, learning and memory. There is evidence which suggests that Bacopa, by the virtue of containing active constituents like bacosides, influences the synthesis and availability of the neurotransmitter, Serotonin; therefore, Bacopa helps to maintain neurotransmitter balance (Charles et al., 2011; Rauf et al., 2012a).

\section{PHARMACOLOGICAL EFFECTS}

\section{Memory Booster in Alzheimer's Disease and Schizophrenia}

Brahmi (Bacopa monniera) has been used in the form of memory enhancer for many years. The accreditation of the traditional assertion of Brahmi was initiated by investigating the effect of an alcoholic extract of this herb on acquisition, consolidation and retention in different conditioning schedules in rats. These included shock driven brightness-discrimination response, continuous avoidance and active conditioned response. It was found that motor skills, acquisition and consolidation were improved and newly acquired behavior was retained for a long period of time in all the three learning responses by the introduction of the CDRI-08 (KeenMind; $40 \mathrm{mg} / \mathrm{kg}$, po. $\times$ 3d) in mice (Singh and Dhawan, 1982, 1997). To discern the efficacy of Brahmi in causing the reversal of amnesia, several behavioral studies have been conducted by inducing amnesic agents in animals. Some of the potential amnesic agents including benzodiazepines, scopolamine, quinoline derivatives and phenytoin cause amnesia by interrupting long-term potentiation (LTP). The process of LTP is probably interfered by the involvement of gamma-aminobutyric acid-benzodiazepine pathway. Saraf et al. demonstrated that amnesia induced by diazepam $(1.75 \mathrm{mg} / \mathrm{kg})$ was significantly reversed by Brahmi $(120 \mathrm{mg} / \mathrm{kg})$ which was provided orally in mice (Prabhakar et al., 2008). Subsequently, the same group later examined the influence exerted by Brahmi on the downstream signaling molecules related to LTP in amnesic mice, which were developed by diazepam (Saraf et al., 2008). The molecular tests revealed that diazepam upregulated the gene expression of inducible nitric oxide synthase (iNOS), mitogen activated protein kinase (MAP kinase) and phosphorylated CREB (pCREB) whereas reduced the expression levels of cAMP response element binding 
(Jujubogenin glucopyranoside])

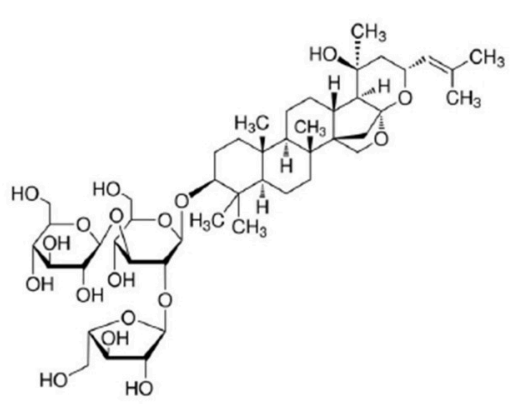

Bacoside A3

3-O-[ $\alpha$-L-arabinofuranosyl- $(1 \rightarrow 2)-O$ - $[\beta$-D-glucopyranosyl- $(1 \rightarrow 3)]-\beta$-D-

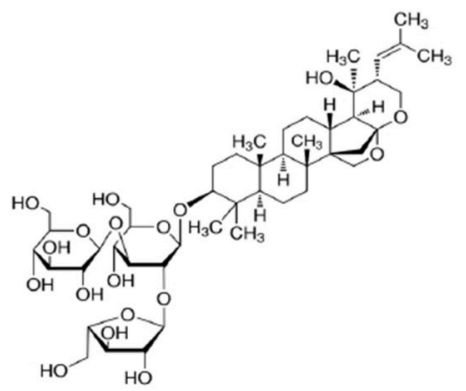

Bacopaside II

(Pseudojujubogenin glucopyranoside])

3-O-[ $\alpha$-L-arabinofuranosyl- $(1 \rightarrow 2)$ - $[\beta-\mathrm{D}$

glucopyranosyl-( $1 \rightarrow 3)]-\beta$-D-

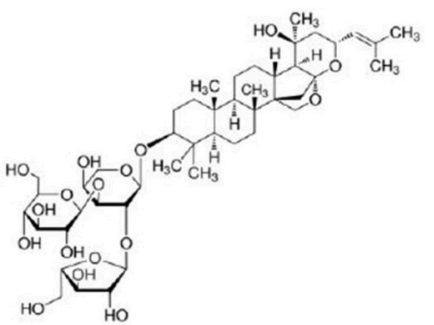

Bacopaside $\mathbf{X}$

Jujubogenin

3-O-[ $\beta$-D-glucopyranosyl-( $\rightarrow 3)$-[ $\alpha$-L-arabinofuranosyl-( $1 \rightarrow 2)]-\alpha$-Larabinopyranoside], Jujubogenin isomer of bacopasaponin $\mathrm{C}$

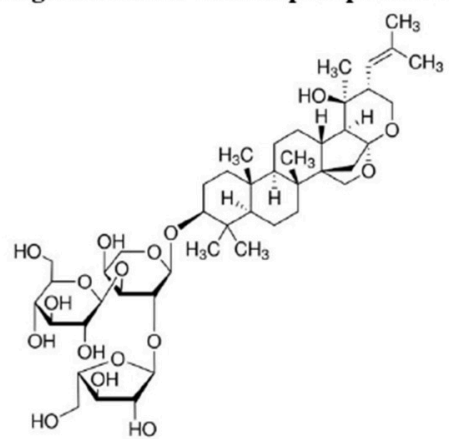

Bacopasaponin $\mathrm{C}$

Pseudojujubogenin arabinopyranoside]

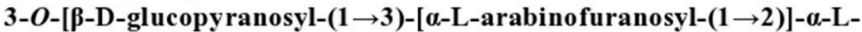


protein (CREB), cyclic adenosine monophosphate (cAMP), total nitrite and nitrate. The levels of calmodulin remained unaltered with diazepam induction. On the contrary, administration of Brahmi inhibited the increased expression of iNOS, pCREB and MAP kinase molecules and restored nitrite level to normal, the expression of which was altered by diazepam. The levels of CAMP, total CREB, total nitrite, nitrate and PDE were found to be unaffected by Brahmi. These behavioral findings provide tempting conclusion that Brahmi reverses amnesia induced by diazepam and can be used in the treatment of Alzheimer's Disease and Schizophrenia.

GABAergic and cholinergic system plays a vital role in reversing the amnesic behavior shown by diazepam and scopolamine. To assess the effect of Brahmi on downstream signaling molecules, amnesia was induced in mice by administrating of MK-801 and N(w)-nitro-L-arginine (L-NNA; Saraf et al., 2009). MK-801 is a NMDA receptor antagonist while L-NNA inhibits the production of nitric oxide that eventually results in memory loss. Morris water maze scale was selected to assess memory and learning skills in animals. It was found that supplementation of both of the amnesic agents in mice resulted in anterograde and retrograde amnesia and that Brahmi significantly reversed the L-NNA induced anterograde and retrograde amnesia. On the contrary, exposure of MK-1 induced mice to Brahmi didn't influence anterograde and reterograde amnesia. This suggests that Brahmi reverses the amnesic effect caused by L-NNA but not with MK-1.

In yet another investigation, scopolamine was used to induce amnesia in mice and the effect of Brahmi was investigated on downstream signaling molecules (Saraf et al., 2010a). The findings revealed that the levels of protein kinase $\mathrm{C}$ and iNOS were downregulated whereas that of protein kinase $\mathrm{A}$, MAP kinase, cAMP, calmodulin, pCREB, CREB and nitrite remained in normal range with the induction of scopolamine. Brahmi overruled the effect of scopolamine in amnesic mice by significantly increasing protein kinase $\mathrm{C}$, calmodulin and $\mathrm{pCREB}$ levels. This shows that Brahmi contributes to prevent memory loss mediated by calmodulin. In addition, Brahmi is reported to significantly reverse L-NNA induced anterograde amnesia instead of MK-801 induced anterograde amnesia (Anand et al., 2010). Moreover, Brahmi ameliorates spatial memory in amnesic model of mice created using scopolamine (Saraf et al., 2011). In this study, the investigating group tested the anti-amnesic effect of Brahmi on amnesia induced by scopolamine using Morris water maze test. Muscle coordination activity in the animals was assessed using the rotarod test. The results revealed that both anterograde and retrograde amnesia produced by scopolamine were reversed by Brahmi treatment (Figure 3). These observations were suggestive of Brahmi's promising potential in the development of alternate approaches in the therapy of Alzheimer's disease. Similarly, Brahmi ameliorated memory impairment induced by phenytoin which further provides evidence for its role as an antiamnesic agent (Vohora et al., 2000). In addition, BN52021 which is a platelet-activating factor receptor antagonist was used to induce retrograde amnesia in mice was also ameliorated by Brahmi treatment. The reason for this might be an increase in glutamate level in the brain, which further increases platelet activating factor synthesis (Kishore and Singh, 2005). Brahmi also plays a neuroprotective role in rat by maintaining the level of mitochondrial enzymes, which got deviated due to morphine induction (Sumathi et al., 2011).

Recently, the neuroprotective effect of Brahmi was investigated in a rat model of schizophrenia (Piyabhan and Wetchateng, 2014). The authors evaluated discrimination ratio as a measure of cognitive ability from novel object recognition task. N-methyl-D- aspartate receptor subtype 1 (NMDAR1) density was also measured in different areas of brain including prefrontal cortex, striatum, cornu ammonis fields I (CA1) and $2 / 3(\mathrm{CA} 2 / 3)$ of hippocampus and dentate gyrus (DG). The findings revealed a significant reduction in discrimination ratio in schizophrenia induced group compared to control. NMDAR1 showed upregulated expression in CA2/3 and DG but not in prefrontal cortex, striatum or CA1. Upon Brahmi administration, the DR score increased up to normal with considerable downregulation of NMDARI in CA2/3 and DG. The mechanism for memory impairment in schizophrenia induced rats appeared to be mediated by upregulation of NMDAR1 in CA2/3 and DG areas of brain. Interestingly, administration of Brahmi could restore this memory impairment by decreasing NMDAR1 in these brain areas. Therefore, Brahmi could be regarded as a novel frontier for the prevention of memory impairment in schizophrenia. The same group previously measured the vesicular glutamate transporter type 1 (VGLUT1) density in same areas of brain and found a significant decrease in the expression of this transporter of rat model of schizophrenia (Piyabhan and Wetchateng, 2013). As expected administration of Brahmi upregulated the expression of this transporter to normal level thereby proving its effectiveness in the treatment of Schizophrenia. Brahmi also possesses antiepileptic property as evidenced by reducing the dopamine levels of dopaminergic neurons in the frontal cortex region of the rat brain (Jash and Chowdary, 2014). These observations suggest that Brahmi may possess the property to alleviate the positive symptoms of schizophrenia.

Khan et al. demonstrated the therapeutic efficacy of Brahmi on intellectual impairment and oxidative damage, induced by streptozotocin in rat models (Khan et al., 2015). The data showed that streptozotocin deteriorated memory and learning skills in these animals, which were significantly improved by Brahmi supplementation. Furthermore, increase in the amount of thiobarbituric acid reactive substances, indicative of lipid peroxidation, were visualized in the brain of these animals. Antioxidant status was also found disturbed in the hippocampus region of the brain along with a decrease in copper and zinc concentration in these experimental animals. Brahmi significantly ameliorated all of these alterations induced by streptozotocin in rats. The data suggests that formation of free radicals and increased rate of lipid peroxidation as a result of streptozotocin induction might cause neurotoxicity in these animals which can be prevented by the use of Brahmi. The study demonstrates the usefulness of Brahmi for the treatment of intellectually impaired patients. 


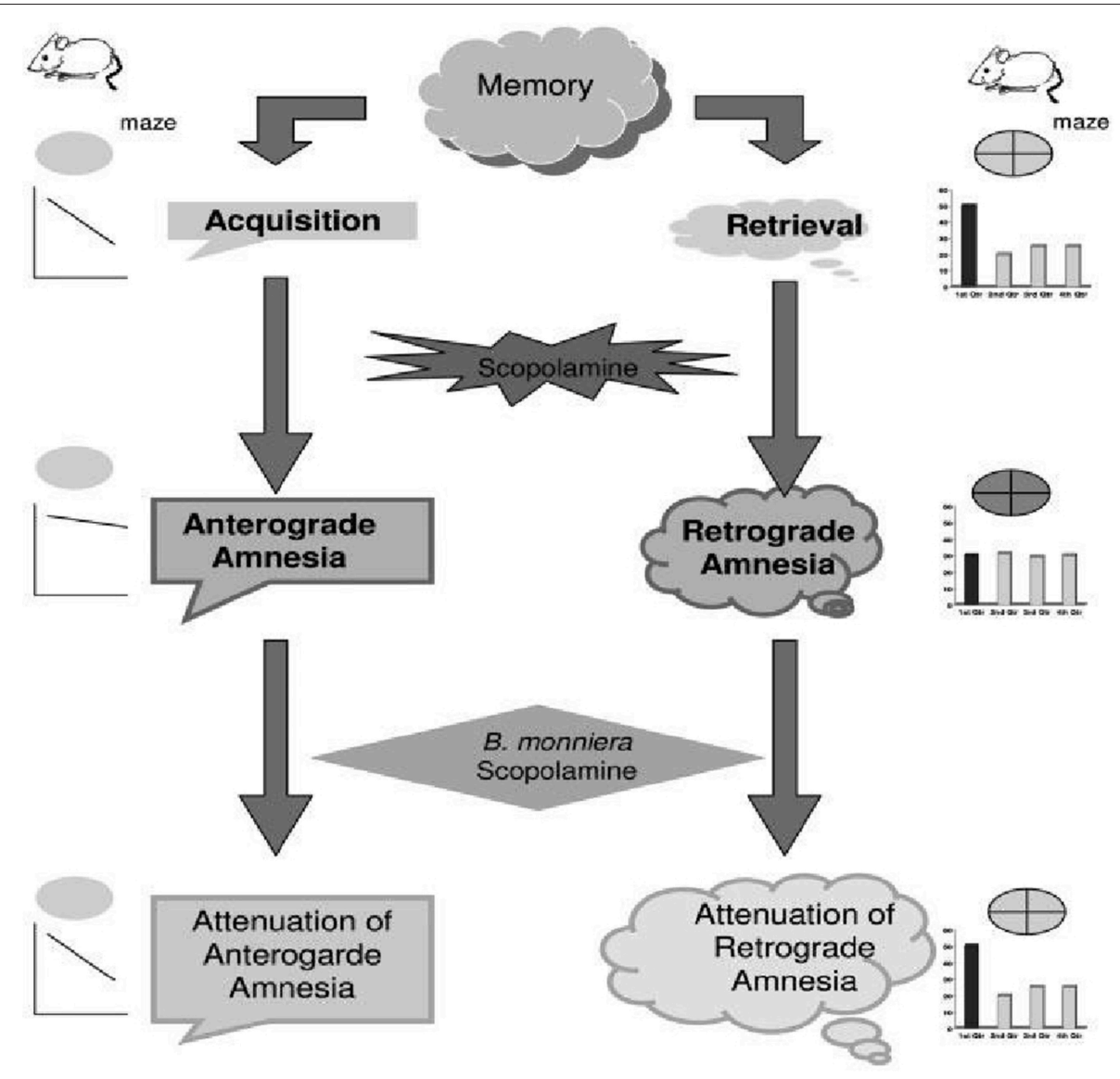

FIGURE 3 | Proposed schematic presentation of effect of $\boldsymbol{B}$. monniera on acquisition and retrieval of memory. The diagram depicts that scopolamine-induced impairment of acquisition and retrieval of memory are reversed by B. monniera pretreatment (Adapted from Saraf et al., 2011).

Brahmi has been reported to increase the level of serotonin, trigger 5-HT3A receptors and CREB in hippocampus of postpartum rats thereby facilitating its learning abilities (Rajan et al., 2011). To identify the mechanism by which Brahmi acts on sodium butyrate $(\mathrm{NaB})$ induced rat pups, the animals were subjected to fear conditioning test (Preethi et al., 2014). Fear conditioning is a behavioral paradigm in which an organism learns to envisage to an aversive stimulus. This stimulus is associated with neutral stimulus that elicits a state of fear response in the organism. The results revealed that Brahmi treatment in $\mathrm{NaB}$ induced rats facilitated the freeze response and triggered extracellular ERK/CREB signaling transduction. The levels of HAT containing coactivators such as p300, acetylated histones (e.g., Ac-H3 and Ac-H4) showed up regulated expression whereas $\operatorname{HDACs}(1,2)$ and protein phosphatases (PP1 $\alpha, \mathrm{PP} 2 \mathrm{~A})$ showed down regulated expression in hippocampus after fear conditioning test. Subsequently, the expression of brain-derived neurotrophic factor (Bdnf) (exon IV) mRNA was found to be increased indicating that Brahmi enhances hippocampus-dependent contextual memory by modulating the expression of histone acetylated proteins and protein phosphatases in hippocampus.

\section{Antiparkinson's Effects}

Apart from alleviating memory, Brahmi is demonstrated to play a role in treating Parkinson's disease, which is a neurodegenerative disorder marked by the loss of neurons which produce dopamine in substancia nigra and alpha-synuclein protein, is accumulated in the inclusion bodies known as lewy bodies (Feany and Bender, 2000). To study the mechanism underlying PD pathogenesis various experimental models have been employed. However, research on evaluating the effect of Brahmi and other plant extracts in PD models is limited. Recently, Siddique et al. investigated the effect of CDRI-08 (KeenMind) in transgenic Drosophila fruit fly (PD model) which expressed normal human alpha synuclein in their neurons. Different parameters including climbing skills, activity pattern, oxidative stress and apoptosis were measured to study the effect of Brahmi in the brain of fruit fly. Their findings revealed an improved climbing ability as well as activity pattern, reduced oxidative stress and apoptosis upon exposure of flies to Brahmi. These findings were dose dependent and suggest that the herb attenuates behavioral deformities, reduces the oxidative stress and neuronal cell death in the brains of PD model flies. Similar findings were obtained by Jansen et al., who also demonstrated the efficacy of Brahmi in alleviating the 
climbing activity of fruit flies compared to non-treated fruit flies (Jansen et al., 2014).

In line with previous research Jadiya et al., employed Caenorhabditis elegans model of Parkinson's disease to investigate the efficacy of this herb. Their findings revealed that Brahmi exposure reduced alpha synuclein accumulation, prevented dopaminergic cell death and restored the lipid content in this PD model. These data provide an evidence for Brahmi to be considered as a possible anti-Parkinsonian medication and further research on the potential use of herbal plants, compounds, and extracts in treating Parkinson's disease is required (Jadiya et al., 2011).

\section{Antistroke Effects}

The medicinal potency of Brahmi in treating Alzheimer's Disease and Parkinson's Disease has already been established. To explore its role in treating brain stroke, few investigations have been conducted by Rehni et al., who explored the role of this herbal plant on ischemia and reperfusion induced brain injury in experimental mice (Rehni et al., 2007). Ischemic-reperfusion induction lead to the increase in infarct size and impairment of short-term memory and motor balance. On the other hand, administration of Brahmi in these mice significantly reduced the infarct size and attenuated their short-term memory and motor balance. In line with this report, Saraf et al. investigated the role of Brahmi in ischemic induced brain injury in rats. Brahmi was supplemeted at a dosage of 120,160 , and $240 \mathrm{mg} / \mathrm{kg}$ in these animals and various behavioral and biochemical analysis were done to screen the efficacy of this herb (Saraf et al., 2010b). Their findings showed a protective role of Brahmi in reducing infarct size in the ischemic brain and ameliorating memory dysfunction as shown in the plus maze task. Additionally, administration of Brahmi improved the muscle coordination and catalase activity in rats exposed to ischemic insult. Levels of nitrite, nitrate and rate of lipid peroxidation were also significantly decreased. These observations indicate that Brahmi protects brain against ischemia-induced insults and further research in this direction is warranted.

Furthermore, brain ischemia reduces blood flow in cerebral arteries due to the lack of oxygen supply. To investigate whether Brahmi exerts any effect on cerebral blood flow (CBF) Kamkaew et al., measured this parameter in rats (Kamkaew et al., 2013). Rats were treated with a dose of $40 \mathrm{mg}$ of Brahmi for a period of 8 weeks and thereafter, the CBF was measured via Doppler. Interestingly, the herb was found to increase the cerebral blood flow (CBF) by $25 \%$ in rats without affecting their blood pressure. These findings further confirm the efficacy of this herb in the treatment of neurological disorders and further research in this direction is required.

\section{Anticonvulsant Effects in the Treatment of Epilepsy}

Epileptic seizures represent a cardinal feature of the neurological syndrome named epilepsy. This disease may affect people of all ages. In recent years, an immense interest has been generated in the search of herbal drugs and formulations that may be used in the treatment of epilepsy. Brahmi is one such widely used herbal drug that alleviates nervous function, enhances memory, and reduces convulsions and inflammation. It has been reported that CDRI-08 (KeenMind) produces anticonvulsive action (Reas et al., 2008). Paulose et al., studied the role played by metabotropic glutamate- 8 receptor (mGluR8) and NMDA receptor 1 (NMDAR1) gene expression in pilocarpine induced epilepsy and during neonatal hypoxia (Paulose et al., 2008). During epilepsy, mGluR8 gene was downregulated whereas NMDAR1 gene showed increased expression in hypoxic neonates. To explore the neuroprotective role of Brahmi, epileptic rats were supplemented with the herbal medication and hypoxia induced rats were supplemented with glucose, oxygen and epinephrine. The findings revealed that Brahmi treatment significantly reversed the downregulation of mGluR8 gene to normal level. Similarly, glucose supplementation together with oxygen supply in hypoxic neonates rescued the NMDAR1 gene expression to normal level. These observations suggest a neuroprotective role of Brahmi in glutamate-mediated excitotoxicity during seizures in pilocarpine-induced epilepsy. A study employed a number of convulsion inducing models including pentylenetetrazol, strychnine, hypoxic stress and pilocarpine to investigate the anticonvulsive activity of Brahmi in rats and mice. Brahmi was administered orally ( 50 and $55 \mathrm{mg} / \mathrm{kg}$ ) in these animals, 2 and $4 \mathrm{~h}$ prior to receiving convulsive stimuli. It was found that the herb produced a significant anticonvulsant activity like benzodiazepines in different convulsion inducing models studied (Kaushik et al., 2009).

CDRI-08 (KeenMind) has been reported to ameliorate pilocarpine induced epilepsy through regulation of 5-HT2C and NMDA receptors in cerebral cortex (Khan et al., 2008; Krishnakumar et al., 2009a,b, 2015). During epileptic condition, the expression of glutamate receptors is altered. 5-HT2C receptor and IP3 (a signal transduction molecule) shows an elevated expression during epileptic state. On the other hand, NMDA receptor shows a downregulated expression in the brain of epileptic animals whereas mGlu5 and GLAST shows an upregulated expression leading to glutamate mediated excitotoxicity. It has been shown that treatment of epileptic rats with Brahmi reverses the changes observed in 5-HT2C, NMDA receptor expression and IP3 content thereby effectively managing the neurotransmitter balance in the cerebral cortex. These observations suggest the neuroprotective role of CDRI-08 (KeenMind) in glutamate-mediated excitotoxicity via regulating altered neurotransmitter receptor expression during seizures observed in pilocarpine induced epilepsy.

\section{Antidepressant Effects}

Brahmi appears to play a plethora of functions in the central nervous system. In addition to its diverse role in treating the diseased brain, the herb shows anti-depressant property. When mice supplemented with CDRI-08 (KeenMind) were subjected to tail suspension test (TST) and forced swimming (FST), the herbal drug exerted antidepressant activity (Shen et al., 2009). The drugs were given orally for 5 days that significantly minimized the immobility time span both in FST and TST. The antidepressant activity of Brahmi was believed to have occurred by some of its components like Bacosides A and B, 
bacopasaponin C, bacopasides I and II and its plant extract. However, bacopaside VII, a constituent of Brahmi, did not reveal any antidepressant activity when analyzed using tail suspension and forced swimming tests (Sairam et al., 2002; Sheikh et al., 2007; Zhou et al., 2007). Banerjee et al. investigated whether treatment with Brahmi produces any antidepressant activity in rats which were made to undergo chronic unpredictable stress based depression (Banerjee et al., 2014). The group used some behavioral tests like sucrose consumption test, shuttle box escape test and open field test to validate this hypothesis. Stress was induced in rats for a period of 4 weeks. This resulted in decreased consumption of sucrose, locomotor activity and escape latency in the animals. In addition, both mRNA and protein content of brain-derived neurotrophic factor (BDNF) showed downregulated expression in both the frontal cortex and hippocampus in CUS treated rats. Supplementation with Brahmi $(80-120 \mathrm{mg} / \mathrm{kg}$ ) greatly suppressed the behavioral changes and attenuated BDNF content to normal in the frontal cortex and hippocampus areas of the rat brain confirming its antidepressant activity.

The antidepressant activity of Brahmi was reported in morphine induced depression in rats (Rauf et al., 2014). Morphine, an opioid analgesic drug, when administered in rats cause depression. The drug was administered everyday two times at a dose of $20-65 \mathrm{mg} / \mathrm{kg}$ for 8 consecutive days. Three days after last morphine administration forced swimming test (FST) was conducted to assess the withdrawal effect of the drug. It was found that Brahmi treatment inhibited the withdrawal effect of the morphine induced depression. Altogether, Brahmi can be considered as a useful adjunct to cure depression like illnesses.

\section{Antianxiety Effects}

CDRI-08 (KeenMind) possess antianxiety effects, antidepressant activity, anticonvulsive action and antioxidant activity (Reas et al., 2008). Supplementation of Brahmi normalized the levels of corticosterone hormone which were imbalanced due to acute and chronic stress induction in rats. The levels of 5-HT, noradrenalin (NA) and dopamine in cortex and hippocampus regions of rats were also brought to normal in acute and chronic unpredictable stress induced animals (Sheikh et al., 2007). Brahmi modulates the cholinergic system and produces metal chelating effects. Cognitive abnormalities produced by neurotoxins, colchicine and ibotenic acid were improved by Brahmi administration in a dose dependent manner in rats (Bhattacharya et al., 2000; Rauf et al., 2012b). Also norepinephrine levels declined and 5-hydroxytryptamine levels were increased in hippocampus, cerebral cortex and hypothalamus by Brahmi treatment. Anxiety was relieved to a greater extent with higher doses of CDRI-08 (KeenMind), which was comparable to lorazepam, a standard drug used in the treatment of anxiety (Bhattacharya and Ghosal, 1998). However, treatment with lower dose of CDRI-08 (KeenMind; 10, 20, or $30 \mathrm{mg} / \mathrm{kg}$ supplemented for 1 week period) did not affect serotonin (5-HT) and dopamine levels in mice brain (Rauf et al., 2012b).

\section{Antioxidant Effects}

Oxidative stress and subsequent formation of free radicals has been implicated in the development of several diseases. Brahmi, a traditionally reputed herbal drug, has been reported to exert antioxidant activity. There are many factors that produce free radical mediated oxidative stress in vivo. Smoke formed from crackers increases the risk of the development of many lung diseases that ultimately results in the formation of oxidative stress. Pandareesh M. and Anand assessed whether Brahmi ameliorates the neuronal damage and physiological changes in rats upon smoke exposure (Pandareesh M. and Anand, 2014). The group exposed the rats to smoke for $1 \mathrm{~h}$ for 3 weeks and treated the animals with Brahmi with three different dosages viz., 10, 20, and $40 \mathrm{mg} / \mathrm{kg}$ body weight. This treatment quenched reactive oxygen species formed as a result of smoke exposure and normalized the pathological changes observed in rat brain. Also, the rate of acetylcholine esterase activity, lipid peroxidation and brain neurotransmitter levels were found to be normal upon Brahmi treatment. The herb also down regulated iNOS expression thereby inhibited nitric oxide generation and HO-1 expression. Antioxidant enzyme concentration and monoamine oxidase activity were also enhanced which were depleted upon smoke exposure. These findings suggest the antioxidant and neuroprotective properties of Brahmi and may be considered as a possible remedy in the treatment of several neurodegenerative disorders.

Furthermore, oxidative stress generated by lead exposure is ameliorated by Brahmi in various areas of rat brain (Velaga et al., 2013). Lead exposure raised the levels of reactive oxygen species (ROS). Also the rate of lipid peroxidation, the carbonyl content in total protein and metal content in different tissues of rat brain. However, Brahmi treatment mitigated the levels of these proteins to normal suggesting its antioxidant property. Similarly, oxidative stress generated by sodium nitroprusside (SNP) was ameliorated by Brahmi treatment in PC12 cells (Pandareesh M. D. and Anand, 2014). In this study, Brahmi inhibited the generation of $\mathrm{NO}$ via down regulating iNOS expression. Heat shock proteins together with apoptotic markers such as Bax, Bcl-2, cytochrome-c and caspase-3 were also modulated to normal, the level of which was imbalanced by SNP exposure in PC12 cells. In addition, sodium nitroprusside (SNP) induced damage to plasma membrane, nuclear membrane and mitochondrial integrity of PC12 cells was ameliorated by Brahmi treatment. These findings suggests a protective and antioxidant role Brahmi exhibits to PC12 cells by mitigating the SNP induced toxicity.

Brahmi also ameliorates decabrominated diphenyl ether (PBDE-209) provoked toxicity in neonate and young female mice (Verma et al., 2014). Different doses of Brahmi (40, 80, or $120 \mathrm{mg} / \mathrm{kg})$ in combination with PBDE-209 $(20 \mathrm{mg} / \mathrm{kg}$ body weight) were administered orally in mice from postnatal day 3 to day 10. Levels of oxidative stress indicators (malondialdehyde, and protein carbonyl) and antioxidant markers (superoxide dismutase and glutathione peroxidase) were measured. The results showed that the dose of $120 \mathrm{mg} / \mathrm{kg}$ of Brahmi restored the levels of oxidants and activities of antioxidant enzymes in the hippocampus and frontal cortex of neonates against PBDE209-induced toxicity. This data suggests that Brahmi renders the brain resistant to PBDE-209 induced toxicity and thus may be better exploited as a preventive approach to protect against oxidative-mediated neuronal dysfunctions. 
Another paraquat (PQ) mediated oxidative stress and neurotoxicity was ameliorated by Brahmi treatment in different brain regions of pre-pubertal mice (Hosamani et al., 2014). Mice were administered CDRI-08 (KeenMind) daily $(200 \mathrm{mg} / \mathrm{kg}$ body weight) for 4 consecutive weeks along with PQ $(15 \mathrm{mg} / \mathrm{kg}$ body weight, intraperitoneally) after $3 \mathrm{~h}$ of last dose of extract. Within 2 days PQ administration resulted in the up regulation of oxidative stress indicating molecules (such as reactive oxygen species (ROS), hydroperoxides (HP) and malondialdehyde (MDA). However, Brahmi restored PQ induced oxidative stress back to normal via suppression of these markers in various brain regions.

Previous studies have demonstrated increased reactive oxygen species formation and cytotoxicity in cells exposed to hydrogen peroxide $\left(\mathrm{H}_{2} \mathrm{O}_{2}\right)$. Hence, $\mathrm{H}_{2} \mathrm{O}_{2}$ has been greatly used to study the effects of antioxidant and cytoprotective role of herbal extracts. Pandareesh et al. studied the effect of $\mathrm{Brahmi}$ on $\mathrm{H}_{2} \mathrm{O}_{2}$ mediated oxidative stress in PC12 and L132 cells (Pandareesh et al., 2014). In this study, cells were treated with $\mathrm{H}_{2} \mathrm{O}_{2}$ for $24 \mathrm{~h}$ with or without Brahmi pretreatment. A couple of tests including cell viability assay, ROS estimation, lipid peroxidation, mitochondria membrane potential assay, comet assay and gene expression studies were conducted to measure the cytoprotective activity of Brahmi. Brahmi scavenged free radicals formed during the process thereby assisting in cytoprotection. Moreover, $\mathrm{H}_{2} \mathrm{O}_{2}$ induced mitochondrial and plasma membrane damage was repaired by Brahmi in both of these cell lines.

Stress is a common and sometimes unavoidable problem that may lead to serious health effects. Investigators are attempting to explore the role of phytochemicals, plant extracts and compounds in modulating the activities of stress associated biomarkers. The levels of stress biomarkers namely Hsp, SOD, and cyt P450 were evaluated to study the effect of Brahmi in stress induced animals. To investigate the antistress effect, the herbal medicine was orally administered ( 20 and $40 \mathrm{mg} / \mathrm{kg}$ ) in rats for 7 successive days (Chowdhuri et al., 2002). Stress induction elevated Hsp expression in brain. However, the protein expression remain unaltered at both doses of Brahmi in all brain regions. Interestingly, pretreatment of animals with Brahmi (7 days period) before stress induction resulted in decreased Hsp expression in all brain areas with more significant reduction in hippocampus region. At the same time, lower dose of Brahmi decreased SOD activity whereas its higher dose increased it in the hippocampus region of the rat brain. Similarly, pretreatment with a lower dose of Brahmi further reduced the SOD activity in each of the brain regions. However, higher dose of Brahmi led to elevation in the enzyme activity in all areas of the brain except cerebellum and hippocampus where it dropped significantly. Similarly stress increased the activity of Cyt P450 in all the brain regions. Almost similar results were observed with both the doses, but the P450 expression reduced with a higher dose of Brahmi. Likewise, animals pretreated with the higher dose of Brahmi followed by stress induction restored the activity of P450 enzymes to near normal levels in animals. These findings indicated the effectiveness of Brahmi in regulating stress biomarker levels and suppoting the brain to combat stressful conditions.
Mathur et al. employed DPPH radical scavenging method to investigate the antioxidant nature of four different extracts of CDRI-08 (KeenMind) in male wistar rats. It was found that all the four different extracts possessed the maximum antioxidant activity (Mathur et al., 2010). Brahmi has also been considered as a valuable supplement in the treatment of cancer and tumor. Janani et al. studied the effects of Brahmi on chemoprevention of liver cancer in an animal model (Janani et al., 2010). The group treated the animals with a carcinogen, which led to an increase in their lipid peroxidation, tumor biomarkers and markers corresponding to liver damage. Eventually, hemolysate and antioxidant status dropped markedly in the liver. Brahmi supplementation recovered the enzyme levels to normal, suppressed lipid peroxidation and enhanced its antioxidant status suggesting its chemoprotective role in the treatment of liver cancer. Similarly, the antioxidant and tumor inhibiting property of Brahmi was studied in 3methylcholanthrene induced fibrosarcoma rats (Rohini et al., 2004). The levels of the antioxidant enzymes such as glutathione peroxidase, superoxide dismutase, catalase and glutathione, the rate of lipid peroxidation (LPO) were determined in the liver and kidney tissues. Sarcoma induction in rats resulted in a marked increase in the rate of LPO and a decrease in the antioxidant enzyme status. Furthermore, tumor markers such as lactate dehydrogenase, alanine transaminase, aspartate transaminase, creatine kinase, and sialic acid showed an upregulated expression in the serum. Brahmi supplementation enhanced the antioxidant enzyme status, reduced the rate of lipid peroxidation and downregulated tumor development markers.

Similar to many previous reports, an investigating group measured the antioxidant and lipid peroxidative status in response to Brahmi supplementation in streptozotocin induced diabetic rats. They provided CDRI-08 (KeenMind) orally to these diseased animals daily for 15 days (dosage: 50, 125, and $250 \mathrm{mg} / \mathrm{kg}$ ). Thereafter, the enzymatic activity of catalase, SOD and GPx, levels of GSH and rate of lipid peroxidation were measured in kidney and brain, with special attention to cerebrum, cerebellum and midbrain. It was found that antioxidant status and peroxidative damage was totally reversed by the administration of plant extract. Activities of SOD, catalase, GPx and levels of GSH were significantly increased in diabetic rats treated with extract (Kapoor et al., 2009). To investigate the antidiabetic effect of this herb, Ghosh et al., treated alloxan induced hyperglycemic rats with CDRI-08 (KeenMind). They found that blood glucose level went down when single and multiple doses of Brahmi were provided to the animals. Weight of the rats was also recovered to normal with Brahmi treatment which was lost during diabetes. CDRI-08 (KeenMind) also inhibited the increase in glycosylated hemoglobin in vitro and reduced thiobarbituric acid reactive substances (TBARS) content. It also increased the levels of glutathione, SOD, catalase activity in liver of diabetic rats. The effect of extract was such that the peripheral glucose utilization was found to be increased in vitro in the diaphragm of diabetic rats, which was proportionate to the effect of insulin (Ghosh et al., 2010). The effects of CDRI08 (KeenMind) $(40 \mathrm{mg} / \mathrm{kg}$ ) were studied on aluminum induced oxidative stress and hippocampus damage in rats (Nannepaga 
et al., 2014). Electron microscopy was used to evaluate any structural changes occurred as a result of aluminum intoxication in the hippocampus region of the rat brain. The enzyme activities of antioxidants such as catalase, glutathione peroxidase and SOD were determined. Aluminum administration induced oxidative damage, which was confirmed by finding increased levels of thiobarbituric acid reactive substances in the rat brain. Treatment with Brahmi for a period of 1 month decreased the levels of thiobarbituric acid reactive substances, and restored antioxidant enzyme levels. Furthermore, electron microscopy results of Brahmi treated rats revealed attenuated vacuolation, lipofuscin deposition and pyramidal cell degeneration in the hippocampus which was induced via aluminum induction. These findings further demonstrate Brahmi an important supplement useful for ameliorating the antioxidant status and inhibiting the oxidative damage occurred in aluminum intoxicated animals.

An in vitro study exploring the potential of Brahmi in cytokine regulation, quenching of reactive oxygen species (ROS), and ameliorating intracellular signaling pathway markers was conducted in splenocytes of F344 rats (different age groups; Priyanka et al., 2013). Firstly, concanavalin exposure induced proliferation of lymphocytes acquired from spleen of F344 rats of specific age groups (3-month-old, 8-9 month old, and 18 month old). These proliferated splenocytes were thereafter treated with different dosages of Brahmi (0.001, 0.01, 0.05, 0.1, and 1\%) and donepezil $(5,10,25,50$, and $100 \mu \mathrm{g} / \mathrm{ml})$. The effect of these drugs was studied via measuring the levels of cytokines, antioxidant markers and different intracellular molecules. It was found that donepezil alone but not Brahmi reduced the lymphocyte proliferation in young rats. Cytokines such as IL2 and IFN- $\gamma$ showed elevated expression with lower doses of Brahmi whereas their expression reduced due to donepezil in rats which were young and early middle-aged. Concanavalin exposure also reduced the activity of antioxidant markers (SOD, CAT, GPx, and GST) in these cells. On the contrary, enhancement in CAT activity was observed in all age groups with Brahmi supplementation whereas in older rats donepezil increased the SOD activity. Likewise the action of GPx and GST biomarkers was enhanced in lymphocytes via both Brahmi and donepezil administration all age groups. Whereas in splenocytes there was an enhancement in the rate of lipid peroxidation and age-related suppression in NO generation. Brahmi along with donepezil raised up NO production in the lymphocytes of early middle-aged and older rats. It is important to note that donepezil could suppress lipid peroxidation splenocytes of only old rats whereas Brahmi could do the same in both early-middleaged and old rats. Similarly the reversal in decline of the pAkt expression was achived by Brahmi in both early middle aged and old rats' lymphocytes. We can conclude that Brahmi alongwith donepezil exert various age-related effects on cytokine generation, antioxidant status and intracellular targets which may further manipulate the therapeutic efficiency of these drugs in various diseases.

\section{Gastrointestinal and Hepatoprotective Effects}

Brahmi has been shown to cure a number of gastrointestinal disorders. A dose of $500 \mathrm{mg} / \mathrm{kg}$ of CDRI-08 (KeenMind) when supplied orally prevented the development of diarrhea in mice. As compared to loperamide $(50 \mathrm{mg} / \mathrm{kg}$ ) Brahmi was able to decrease the frequency of defecation suggesting its role as an anti-diarrhoeal herb (Siraj et al., 2012). Also, the fresh juice of this herbal medicine has been shown to prevent the formation of ulcers (Rao et al., 2000). In this study, the group assessed the prophylactic and healing effects CDRI-08 (KeenMind) exerts in five different models of gastric ulcers. It was found that the extract $(20 \mathrm{mg} / \mathrm{kg}$ for 10 consecutive days) alleviated acetic acid induced penetrating ulcers, strengthened mucosal barrier and reduced mucosal exfoliation by reducing the rate of lipid peroxidation in gastric mucosa of rat. The extract has also been reported to produce anti-Helicobacter pylori activity (Sairam et al., 2001; Goel et al., 2003). A randomized, double-blind, placebo controlled clinical trial of 169 irritable bowel syndrome patients, was conducted to assess the therapeutic capacity of an Ayurvedic preparation containing Brahmi and Aegle marmelos herbs. These herbal drugs were provided orally to the patients three times daily for a period of 6 weeks. The effect of ayurvedic treatment was highly beneficial in curing the disease. However, the extent of Brahmi's efficacy could not be predicted as both the drugs were given at the same time to the patients (Yadav et al., 1989).

CDRI-08 (KeenMind) has been found to exert hepatoprotective effect in rats by alleviating antioxidant enzymes status induced by morphine (Sumathi et al., 2011). It was found that morphine induction increased the rate of lipid peroxidation and decreased antioxidant enzyme status in rats. This toxicity induced as a result of morphine induction was nullified by the supplementation of Brahmi.

\section{Endocrine Effects}

The potential of Brahmi in treating endocrine related abnormalities has been documented in a few animal studies. CDRI-08 (KeenMind; $200 \mathrm{mg} / \mathrm{kg}$ orally) has been shown to alter the secretion of thyroid hormone in male mice (Kar et al., 2002). The synthesis of $T 4$ hormone was increased by $41 \%$ via Brahmi intake. However, T3 synthesis was unaffected by the drug supplement indicating that the drug might not be involved in T4 to T3 conversion. Furthermore, Brahmi has been demonstrated to possess the anti-fertility ability in male mouse (Singh and Singh, 2009).

\section{Antimicrobial Effects}

Methanolic extracts of CDRI-08 (KeenMind) have been reported to possess antimicrobial activity as compared to other extracts (Azad et al., 2012; Katoch et al., 2014). In this study, hexane and petroleum ether extracts inhibited the growth of microbes in a similar manner but the effect was less considerable in comparison to methanolic extracts whereas the aqueous extract of CDRI-08 (KeenMind) did not show anti-microbial activity (Hosamani et al., 2014). The growth of Staphylococcus aureus was inhibited to a greater extent by the methanolic extract $(1 \mathrm{mg} / \mathrm{ml})$ of CDRI-08 (KeenMind) in comparison to Salmonella typhi and Eschirichia coli. However, the extract did not suppress the growth of K. pneumonia microbe (Rohini et al., 2004). 


\section{Anti-Inflammatory and Painkiller Effects}

Brahmi, known for its anti-inflammatory and pain relieving effects, acts by selectively inhibiting cyclo-oxygenase- 2 enzyme, and consequently reducing prostaglandins synthesis. Jain et al. demonstrated that CDRI-08 (KeenMind) could effectively suppress the experimentally produced inflammatory reaction by quenching the synthesis of prostaglandins and preventing lyosomal membranes from rupture. Also, treatment with anti-inflammatory dose of Brahmi didn't cause any gastric problems (Jain et al., 1994). Writhing produced by acetic acid in mice was reduced using whole plant ethanol extract of CDRI-08 (KeenMind) (250 and $500 \mathrm{mg} / \mathrm{kg}$; Rao et al., 2000). Mathur et al. used different extracts of CDRI-08 (KeenMind) and studied their anti-inflammatory effects in edema caused by carrageenan in rat's hind paws. Supplements including methanolic and aqueous extract $(100 \mathrm{mg} / \mathrm{kg})$ of Brahmi were found to significantly reduce inflammation, while, petroleum ether and hexane extracts produced no effect (Janani et al., 2010). Also, it was found that methanolic extract (100, 200, $300 \mu \mathrm{g})$ assisted in membrane stabilization as compared to diclofenac sodium (Rohini et al., 2004). Interleukin-6 and tumor necrosis factor-alpha synthesis was inhibited by the fractions of Brahmi containing triterpenoids and bacosides (Viji and Helen, 2011). Furthermore, proinflammatory cytokines such as nitric oxide and TNF- $\alpha$ showed down regulated expression in stimulated macrophages and IFN- $\gamma$ in stimulated human blood cells (Williams et al., 2014). These results provide further evidences that confirm the efficacy of Brahmi in the treatment of brain inflammation.

\section{Relaxant Effects on Smooth and Cardiac Muscles}

Investigations exploring the potential of CDRI-08 (KeenMind) in relaxing cardiac and smooth muscles have been demonstrated in experimental animals. The herbal extract ameliorates left ventricular contractility, coronary blood flow and heart rate in rabbit's heart (Rashid et al., 1990). It also relaxes bronchial smooth muscles, pulmonary arteries, aorta, and trachea. Apparently, the mechanism of action Brahmi exerts on the cardiac muscles is quite similar to that of quinidine. These effects possibly were mediated by accumulation of calcium ions in the extracellular space (Dar and Channa, 1997, 1999; Channa et al., 2003). Furthermore, CDRI-08 (KeenMind) stabilizes the activity of mast cells comparable to disodium cromoglycate (Samiulla et al., 2001).

\section{CLINICAL TRIALS}

Traditionally Brahmi is known to ameliorate cognitive function. This viewpoint has now been scientifically tested through a handful of randomized, double-blind, placebo-controlled clinical trials and nearly all have shown promising results. (Singh et al., 2014) found that supplementation of $12 \mathrm{~g}$ of Brahmi improved the nervousness, concentration and memory in adults. The dose was given to 35 adults in the form of syrup for 4 weeks. There was no complaint of side effects (Singh and Singh, 1980). Similar observations were confirmed by Sharma et al. who studied the effect of Brahmi in 20 primary school children (Sharma et al., 1987). A dosage of $350 \mathrm{mg}$ was given in syrup form three times a day for 3 months. The herb improved learning skills, perception, memory and reaction times in them without the occurrence of any side effects. A randomized and double-blind placebo-controlled trial in 36 children was conducted, who were affected with attention deficit hyperactivity disorder (ADHD) was conducted (Negi et al., 2000). The results were highly beneficial with Brahmi supplementation as it greatly improved the logical memory. In this study, freshly preperaed whole plant extract of Brahmi was administered at a dosage of $50 \mathrm{mg}$ two times a day for a period of 12 weeks. Later, cognitive function tests were performed at various time points which included baseline, $4,8,12$, and 16 weeks. Recovery was observed in the 12 weeks group, consolidated by different cognitive tests. A placebo controlled study demonstrated enhanced learning and controlled abnormal behavior in 40 mentally retarded children consuming standardized extract of CDRI-08 (KeenMind; Dave et al., 1993). Another randomized, double-blind, placebo-controlled trial proved the effectiveness of Brahmi in ameliorating memory (Roodenrys et al., 2002). In this study, 76 healthy adults, 40-65 years old, were supplemented with Brahmi (dose $300 \mathrm{mg}$ ) and they all were benefitted by retaining the information in delayed recall of word pairs. However, there were a few parameters which failed to show the beneficial effect of Brahmi. These include attention, working memory, short-term memory tasks, psychological state and retrieval of prior knowledge. Likewise, no effect of Brahmi (300 mg dosage) on various measures of memory performance was found when it was administered $2 \mathrm{~h}$ after treatment suggesting that its benefits are obtained after long-term use (Nathan et al., 2001). The same group of investigators later found no significant effect of Brahmi (300 mg/day) on cognition and memory when provided in combination with Ginko biloba $120 \mathrm{mg} /$ day for a period of 4 weeks. This was a randomized, placebo-controlled, double-blinded clinical trial, conducted in 85 healthy subjects (Nathan et al., 2004). Bacomind ${ }^{\mathrm{TM}}$ capsule when consumed orally (at a dose of $300 \mathrm{mg}$ once a day for first 15 days and $450 \mathrm{mg}$ once a day for next 15 days) improved mental functioning in 23 healthy adults (Pravina et al., 2007).

A placebo-controlled and double-blinded 12-week clinical trial was carried out to investigate the effectiveness of CDRI-08 (KeenMind) (300 mg daily for 12 weeks) on 46 healthy people aged between 18 and 60 years. A series of cognition function tests were conducted at baseline and later on after 5 and 12 weeks. At the end of 12 weeks, in the treatment group a significant enahncement in verbal learning and concentration was noticed compared to non-treated groups. These effects were not observed at baseline or at 5 weeks of treatment (Stough et al., 2001). Likewise many other clinical trials were conducted to determine the effect of Brahmi on memory function in elderly people above the age of 55 years. They all used same criteria with same amount of dosage and period of administration. It was found that aged people were able to acquire, store and retain their memory over time by consuming Brahmi as a supplement (Calabrese et al., 2008; Morgan and Stevens, 2010). Another randomized double-blind placebo-controlled clinical trial examining the 
TABLE 1 | Clinical trials of Brahmi.

\begin{tabular}{|c|c|c|c|c|c|}
\hline $\begin{array}{l}\text { Study } \\
\text { design }\end{array}$ & Subjects & $\begin{array}{l}\text { Dosage of } \\
\text { Brahmi/day }\end{array}$ & $\begin{array}{l}\text { Time span of the } \\
\text { drug } \\
\text { administration }\end{array}$ & Results & References \\
\hline- & 35 adults & 12 gm/day & 4 weeks & $\begin{array}{l}\text { Reduced anxiety, enhanced memory span } \\
\text { and concentration. } \\
\text { No side effects observed. }\end{array}$ & Singh and Singh, 1980 \\
\hline- & $\begin{array}{l}20 \text { primary school } \\
\text { children }\end{array}$ & $350 \mathrm{mg} \times 3 /$ day & 3 months & $\begin{array}{l}\text { Enhanced memory, learning, perception and } \\
\text { reaction times. No side effects observed. }\end{array}$ & Sharma et al., 1987 \\
\hline PC & $\begin{array}{l}40 \text { Mentally } \\
\text { retarded children } \\
\text { with or without } \\
\text { epilepsy }\end{array}$ & CDRI-08 (KeenMind) & - & $\begin{array}{l}\text { Enhanced learning and controlled abnormal } \\
\text { behavior. }\end{array}$ & Dave et al., 1993 \\
\hline $\begin{array}{l}\text { RA, DB, } \\
\text { PC }\end{array}$ & $\begin{array}{l}36 \text { children with } \\
\text { Attention deficit } \\
\text { hyperactivity } \\
\text { disorder (ADHD) }\end{array}$ & $50 \mathrm{mg} \times 2 /$ day & 12 weeks & $\begin{array}{l}\text { Ameliorated various cognitive assessments. } \\
\text { No side effects observed. }\end{array}$ & Negi et al., 2000 \\
\hline- & $\begin{array}{l}38 \text { healthy } \\
\text { subjects }\end{array}$ & 300 mg/day & $\begin{array}{l}2 \mathrm{~h} \text { post } \\
\text { administration }\end{array}$ & No improvement in memory performance. & Nathan et al., 2001 \\
\hline $\mathrm{DB}, \mathrm{PC}$ & 46 healthy people & 300 mg/day & 12 weeks & $\begin{array}{l}\text { Improved early information processing and } \\
\text { verbal learning rate. Consolidated memory } \\
\text { and reduced state anxiety. Side effects: } \\
\text { nausea, dry mouth and fatigue. }\end{array}$ & Stough et al., 2001 \\
\hline $\begin{array}{l}\text { RA, DB, } \\
\text { PC }\end{array}$ & 76 healthy adults & 300 mg/day & 12 weeks & Enhanced retention of new information. & Roodenrys et al., 2002 \\
\hline $\begin{array}{l}\text { RA, DB, } \\
\text { PC }\end{array}$ & $\begin{array}{l}85 \text { healthy } \\
\text { subjects }\end{array}$ & $\begin{array}{l}\text { Combination of } \\
\text { standardized CDRI-08 } \\
\text { (KeenMind) } 300 \text { mg/day } \\
\text { and Ginko biloba } 120 \\
\text { mg/day }\end{array}$ & 4 weeks & $\begin{array}{l}\text { No significant effect on cognition and } \\
\text { memory. }\end{array}$ & Nathan et al., 2004 \\
\hline $\begin{array}{l}\text { RA, OL, } \\
\text { DE }\end{array}$ & $\begin{array}{l}23 \text { healthy adult } \\
\text { volunteers }\end{array}$ & $\begin{array}{l}\text { Bacomind }^{\mathrm{TM}} \text { capsule } \\
300 \mathrm{mg} / \text { day } \text { and } 450 \mathrm{mg}\end{array}$ & $\begin{array}{l}15 \text { days each, } \\
\text { respectively }\end{array}$ & $\begin{array}{l}\text { Improved cognition. Minor gastrointestinal } \\
\text { adverse effects. }\end{array}$ & Pravina et al., 2007 \\
\hline $\begin{array}{l}\text { RA, DB, } \\
\text { PC }\end{array}$ & 54 healthy adults & $\begin{array}{l}\text { Standardized CDRI-08 } \\
\text { (KeenMind) } 300 \text { mg/day }\end{array}$ & 12 weeks & $\begin{array}{l}\text { Enhanced cognitive performance in the } \\
\text { aging. }\end{array}$ & Calabrese et al., 2008 \\
\hline $\begin{array}{l}\text { RA, DB, } \\
\text { PC }\end{array}$ & 98 healthy adults & $\begin{array}{l}\text { Bacomind }{ }^{\mathrm{TM}} \text { capsule } \\
300 \mathrm{mg}\end{array}$ & 12 weeks & $\begin{array}{l}\text { A significant improvement in memory } \\
\text { acquisition and retention was observed. } \\
\text { Gastrointestinal side effects reported. }\end{array}$ & $\begin{array}{l}\text { Morgan and Stevens, } \\
2010\end{array}$ \\
\hline $\begin{array}{l}\text { RA, DB, } \\
\text { PC }\end{array}$ & 465 participants & 300 mg/day & 12 months & Improvement in memory function. & Stough et al., 2012 \\
\hline $\begin{array}{l}\text { RA, DB, } \\
\text { PC }\end{array}$ & 60 healthy adults & 300 mg/day & 12 weeks & $\begin{array}{l}\text { Attention, cognitive processing, and working } \\
\text { memory improved. }\end{array}$ & Peth-Nui et al., 2012 \\
\hline $\begin{array}{l}\text { RA, DB, } \\
\text { PC }\end{array}$ & $\begin{array}{l}109 \text { healthy } \\
\text { subjects and } 123 \\
\text { SDAT patients }\end{array}$ & $500 \mathrm{mg} \times 2 /$ day & 12 months & $\begin{array}{l}\text { Improvements in memory performance and } \\
\text { reduction in the levels of inflammatory and } \\
\text { oxidative stress markers observed in Brahmi } \\
\text { treated SDAT patients. }\end{array}$ & Sadhu et al., 2014 \\
\hline $\begin{array}{l}\mathrm{PC}, \mathrm{NC} \\
\mathrm{MC}\end{array}$ & $\begin{array}{l}104 \text { elderly } \\
\text { subjects with mild } \\
\text { cognitive } \\
\text { impairment }\end{array}$ & 1 Illumina ${ }^{\circledR}$ tablet/day & 60 days & $\begin{array}{l}\text { Cognitive function improved. One non } \\
\text { serious adverse effect reported. }\end{array}$ & Zanotta et al., 2014 \\
\hline $\mathrm{DB}, \mathrm{PC}$ & $\begin{array}{l}17 \text { healthy } \\
\text { volunteers }\end{array}$ & $320 \mathrm{mg}$ and $640 \mathrm{mg}$ & & $\begin{array}{l}\text { Brahmi supplementation reduced stress and } \\
\text { alleviated mood in these participants. }\end{array}$ & Benson et al., 2014 \\
\hline
\end{tabular}

RA, Randomized; DB, Double-blind; PC, Placebo-controlled; OL, Open label; DE, Dose escalation; PC, Prospective cohort; NC, Noncomparative; MC, Multicenter.

effect of Brahmi on cognitive, biochemical and cardiovascular performance was conducted in elderly people (Morgan and Stevens, 2010). This study involved a large number of randomly selected participants (465 participants) aged between 60 and 75 years. CDRI-08 (KeenMind) ( $300 \mathrm{mg} /$ day) was given to them for a period of 12 months. The participants underwent a series of cognitive function tests at points: baseline, 3, 6, and 12 months and expectedly, the results revealed a significant improvement in their memory function which suggests the effectiveness of Brahmi to be used as a memory booster.

Peth Nui et al. tested different aspects of brain function like attention, cholinergic and monoaminergic functions, memory processing and working memory-using Brahmi. They recruited 60 healthy adults aged around 60 years for a randomized, 
double-blind, placebo-controlled clinical trial. The period of Brahmi administration and dosage was similar to previous studies (300 mg for 12 weeks; Peth-Nui et al., 2012). AChE and MAO activities were measured to evaluate the cholinergic and monoaminergic systems functions. On the contrary, percent accuracy and reaction time was examined to determine the working memory. Latencies and amplitude of N100 were used to measure attention and cognitive processing. The findings of this study revealed a reduction in both N100 and P300 latencies and improvement on working memory with Brahmi supplementation. Furthermore, AChE activity was also found to be decreased suggesting that Brahmi can ameliorate cognitive processing, working memory and attention partly through the reduction of AChE activity. In another similar kind of clinical trial involving healthy elderly subjects and others suffering from senile dementia of Alzheimer's type (SDAT), behavioral and biochemical parameters like learning abilities, inflammatory markers and oxidative stress were measured (Sadhu et al., 2014). A number of cognitive function tests were employed after every 3 months to evaluate the potential of Brahmi in these people. It was found that Brahmi treated SDAT patients improved memory performance when compared to controls. The levels of inflammatory markers like homocysteine, C-reactive protein, and tumor necrosis factor alpha; oxidative stress markers like glutathione peroxidase, glutathione, thiobarbituric acid reactive substances and SOD showed a marked decline in Brahmi treated SDAT patients. This suggests the significance of the herb in managing cognitive decline associated with the aging process. Another multicenter clinical trial involving patients with mild cognitive impairment used similar criteria and obtained favorable results establishing the role of Brahmi in improving cognitive function (Zanotta et al., 2014).

Recently, the acute effects of Brahmi (320 and $640 \mathrm{mg}$ doses) on stress and mood swings generated by multitasking were demonstrated in a double-blind, placebo-controlled clinical trial involving 17 healthy volunteers (Benson et al., 2014).

\section{REFERENCES}

Anand, A., Saraf, M. K., and Prabhakar, S. (2010). Antiamnesic effect of b. Monniera on l-nna induced amnesia involves calmodulin. Neurochem. Res. 35, 1172-1181. doi: 10.1007/s11064-010-0171-x

Azad, A., Awang, M., and Rahman, M. (2012). Phytochemical and microbiological evaluation of a local medicinal plant bacopa monnieri (1.) penn. Int. J. Curr. Pharm. Rev. Res. 3, 66-78.

Banerjee, R., Hazra, S., Ghosh, A. K., and Mondal, A. C. (2014). Chronic administration of bacopa monniera increases bdnf protein and mrna expressions: a study in chronic unpredictable stress induced animal model of depression. Psychiatry Invest. 11, 297-306. doi: 10.4306/pi.2014.11.3.297

Basu, N., Rastogi, R., and Dhar, M. L. (1967). Chemical examination of bacopa mienniera wettst: part iii-bacoside b. Ind. J. Chem. 5, 84-95.

Benson, S., Downey, L. A., Stough, C., Wetherell, M., Zangara, A., and Scholey, A. (2014). An acute, double-blind, placebo-controlled cross-over study of $320 \mathrm{mg}$ and $640 \mathrm{mg}$ doses of bacopa monnieri (cdri 08) on multitasking stress reactivity and mood. Phytother. Res. 28, 551-559. doi: 10.1002/ptr.5029

Bhattacharya, S. K., and Ghosal, S. (1998). Anxiolytic activity of a standardized extract of bacopa monniera: an experimental study. Phytomedicine 5, 77-82. doi: 10.1016/S0944-7113(98)80001-9
Brahmi supplementation reduced stress as observed by reduction in cortisol levels and alleviated mood in these participants. Altogether, these studies demonstrate the therapeutic efficacy of Brahmi in alleviating various abnormalities hence can be considered as a promising frontier to treat various diseases. Table 1 indicates clinical trials of Brahmi.

\section{FUTURE DIRECTIONS}

The therapeutic effects of Brahmi have been extensively investigated by various research groups. It is believed that the bacosides, act as active constituents of the herbal extract which are predominantly involved in exerting the nootropic effects in both animals and humans. The delivery of active components to brain itself is a challenging task, which can be solved to great extend by nanoscience. As nanoscience has emerged as a subject of significant curiosity which associated with special properties like surface to volume ratio and surface reactivity. Drug delivery to the brain represents one of the most important challenges in the field of nanomedicine. At the same time, a better understanding of the physiopathological nature of different diseases associated to cognitive science and insight into the interaction of nanomaterials with biological systems at various levels (i.e., systemic, organ, tissue, and cell) are of paramount importance for further progress toward bench-tobedside translation or the mechanisms underlying the effects of Brahmi in various disease conditions need to be elucidated extensively at the molecular level and followed by clinical trials. In order to make the extract/ active components targeted to brain, use of targeted nanoparticles based on liposomes, polymeric micelles, polymersomes can be considered as an important tool.

\section{AUTHOR CONTRIBUTIONS}

DM and KG wrote the manuscript. AA and VK conceptualized and edited the manuscript.

Bhattacharya, S. K., Kumar, A., and Ghosal, S. (2000). "Effect of bacopa monniera on animal models of Alzheimer's disease and perturbed central cholinergic markers of cognition in rats," in Molecular Aspects of Asian Medicines, ed D. V. Siva Sanka (New York, NY: PJD), 21-32.

Calabrese, C., Gregory, W. L., Leo, M., Kraemer, D., Bone, K., and Oken, B. (2008). Effects of a standardized bacopa monnieri extract on cognitive performance, anxiety, and depression in the elderly: a randomized, doubleblind, placebo-controlled trial. J. Alter. Complement. Med. 14, 707-713. doi: 10.1089/acm.2008.0018

Channa, S., Dar, A., Yaqoob, M., Anjum, S., and Sultani, Z. (2003). Bronchovasodilatory activity of fractions and pure constituents isolated from bacopa monniera. J. Ethnopharmacol. 86, 27-35. doi: 10.1016/S0378-8741(03)00013-8

Charles, P. D., Ambigapathy, G., Geraldine, P., Akbarsha, M. A., and Rajan, K. E. (2011). Bacopa monniera leaf extract up-regulates tryptophan hydroxylase (tph2) and serotonin transporter (sert) expression: implications in memory formation. J. Ethnopharmacol. 134, 55-61. doi: 10.1016/j.jep.2010. 11.045

Chatterji, N., Rastogi, R., and Dhar, M. L. (1965). Chemical examination of bacopa monniera wettst: Part II. The constitution of bacoside A. Ind. J. Chem. 1:212.

Chowdhuri, D. K., Parmar, D., Kakkar, P., Shukla, R., Seth, P., and Srimal, R. (2002). Antistress effects of bacosides of bacopa monnieri: modulation of hsp70 
expression, superoxide dismutase and cytochrome p450 activity in rat brain. Phytother. Res. 16, 639-645. doi: 10.1002/ptr.1023

Dar, A., and Channa, S. (1997). Relaxant effect of ethanol extract of bacopa monniera on trachea, pulmonary artery and aorta from rabbit and guinea-pig. Phytother. Res. 11, 323-325.

Dar, A., and Channa, S. (1999). Calcium antagonistic activity of bacopa monniera on vascular and intestinal smooth muscles of rabbit and guinea-pig. J. Ethnopharmacol. 66, 167-174. doi: 10.1016/S0378-8741(98)00240-2

Dave, U. P., Chauvan, V., and Dalvi, J. (1993). Evaluation of br-16 a (mentat) in cognitive and behavioural dysfunction of mentally retarded children-a placebo-controlled study. Ind. J. Pediatr. 60, 423-428. doi: 10.1007/BF02751207

Deepak, M., and Amit, A. (2013). 'Bacoside B'-the need remains for establishing identity. Fitoterapia 87, 7-10. doi: 10.1016/j.fitote.2013.03.011

Dutta, T., and Basu, U. P. (1963). Terpenoids: Part II-Isolation of new triterpene saponin, monnierin, from Bacopa monniera Wettst. Ind. J. Chem. 1, 400-408.

Feany, M. B., and Bender, W. W. (2000). A drosophila model of parkinson's disease. Nature 404, 394-398. doi: 10.1038/35006074

Ganzera, M., Gampenrieder, J., Pawar, R. S., Khan, I. A., and Stuppner, H. (2004). Separation of the major triterpenoid saponins in bacopa monnieri by highperformance liquid chromatography. Anal. Chim. Acta 516, 149-154. doi: 10.1016/j.aca.2004.04.002

Ghosh, T., Maity, T. K., Sengupta, P., Dash, D. K., and Bose, A. (2010). Antidiabetic and in vivo antioxidant activity of ethanolic extract of bacopa monnieri linn. Aerial parts: a possible mechanism of action. Iran. J. Pharm. Res. 7, 61-68.

Goel, R., Sairam, K., Babu, M. D., Tavares, I., and Raman, A. (2003). In vitro evaluation of bacopa monniera on anti-helicobacter pylori activity and accumulation of prostaglandins. Phytomedicine 10, 523-527. doi: $10.1078 / 094471103322331494$

Hosamani, R., Krishna, G., and Muralidhara. (2014). Standardized bacopa monnieri extract ameliorates acute paraquat-induced oxidative stress, and neurotoxicity in prepubertal mice brain. Nutr. Neurosci. doi: 10.1179/ 1476830514Y.0000000149. [Epub ahead of print].

Jadiya, P., Khan, A., Sammi, S. R., Kaur, S., Mir, S. S., and Nazir, A. (2011). Anti-parkinsonian effects of bacopa monnieri: insights from transgenic and pharmacological caenorhabditis elegans models of parkinson's disease. Biochem. Biophys. Res. Commun. 413, 605-610. doi: 10.1016/j.bbrc.2011.09.010

Jain, P., Khanna, N., Trehan, N., Pendse, V., and Godhwani, J. (1994). Antiinflammatory effects of an ayurvedic preparation, brahmi rasayan, in rodents. Ind. J. Exp. Biol. 32, 633-636.

Janani, P., Sivakumari, K., Geetha, A., Ravisankar, B., and Parthasarathy, C. (2010). Chemopreventive effect of bacoside a on n-nitrosodiethylamineinduced hepatocarcinogenesis in rats. J. Cancer Res. Clin. Oncol. 136, 759-770. doi: $10.1007 / \mathrm{s} 00432-009-0715-0$

Jansen, R., Brogan, B., Whitworth, A., and Okello, E. (2014). Effects of five ayurvedic herbs on locomotor behaviour in a drosophila melanogaster parkinson's disease model. Phytother. Res. 28, 1789-1795. doi: 10.1002/ptr.5199

Jash, R., and Chowdary, K. A. (2014). Ethanolic extracts of alstonia scholaris and bacopa monniera possess neuroleptic activity due to anti-dopaminergic effect. Pharmacognosy Res. 6, 46. doi: 10.4103/0974-8490.122917

Kamkaew, N., Norman Scholfield, C., Ingkaninan, K., Taepavarapruk, N., and Chootip, K. (2013). Bacopa monnieri increases cerebral blood flow in rat independent of blood pressure. Phytother. Res. 27, 135-138. doi: $10.1002 /$ ptr.4685

Kapoor, R., Srivastava, S., and Kakkar, P. (2009). Bacopa monnieri modulates antioxidant responses in brain and kidney of diabetic rats. Environ. Toxicol. Pharmacol. 27, 62-69. doi: 10.1016/j.etap.2008.08.007

Kar, A., Panda, S., and Bharti, S. (2002). Relative efficacy of three medicinal plant extracts in the alteration of thyroid hormone concentrations in male mice. J. Ethnopharmacol. 81, 281-285. doi: 10.1016/S0378-8741(02)00048-X

Katoch, M., Singh, G., Sharma, S., Gupta, N., Sangwan, P. L., and Saxena, A. K. (2014). Cytotoxic and antimicrobial activities of endophytic fungi isolated from bacopa monnieri (l.) pennell (scrophulariaceae). BMC Complement. Altern. Med. 14:52. doi: 10.1186/1472-6882-14-52

Kaushik, D., Tripathi, A., Tripathi, R., Ganachari, M., and Khan, S. A. (2009). Anticonvulsant activity of bacopa monniera in rodents. Braz. J. Pharm. Sci. 45, 643-649. doi: 10.1590/S1984-82502009000400006

Khan, M. B., Ahmad, M., Ahmad, S., Ishrat, T., Vaibhav, K., Khuwaja, G., et al. (2015). Bacopa monniera ameliorates cognitive impairment and neurodegeneration induced by intracerebroventricular-streptozotocin in rat: behavioral, biochemical, immunohistochemical and histopathological evidences. Metab. Brain Dis. 30, 115-127. doi: 10.1007/s11011-014-9593-5

Khan, R., Krishnakumar, A., and Paulose, C. (2008). Decreased glutamate receptor binding and nmda $\mathrm{r} 1$ gene expression in hippocampus of pilocarpine-induced epileptic rats: neuroprotective role of bacopa monnieri extract. Epilepsy Behav. 12, 54-60. doi: 10.1016/j.yebeh.2007.09.021

Kishore, K., and Singh, M. (2005). Effect of bacosides, alcoholic extract of bacopa monniera linn.(brahmi), on experimental amnesia in mice. Ind. J. Exp. Biol. $43,640$.

Krishnakumar, A., Abraham, P. M., Paul, J., and Paulose, C. (2009a). Downregulation of cerebellar 5 -ht $2 \mathrm{c}$ receptors in pilocarpine-induced epilepsy in rats: therapeutic role of bacopa monnieri extract. J. Neurol. Sci. 284, 124-128. doi: $10.1016 /$ j.jns.2009.04.032

Krishnakumar, A., Anju, T., Abraham, P. M., and Paulose, C. (2015). Alteration in 5 -ht $2 \mathrm{c}, \mathrm{nmda}$ receptor and ip3 in cerebral cortex of epileptic rats: restorative role of bacopa monnieri. Neurochem. Res. 40, 216-225. doi: 10.1007/s11064$014-1472-2$

Krishnakumar, A., Nandhu, M., and Paulose, C. (2009b). Upregulation of 5-ht 2c receptors in hippocampus of pilocarpine-induced epileptic rats: antagonism by bacopa monnieri. Epilepsy Behav. 16, 225-230. doi: 10.1016/j.yebeh.2009.07.031

Mathur, A., Verma, S. K., Purohit, R., Singh, S. K., Mathur, D., Prasad, G., et al. (2010). Pharmacological investigation of bacopa monnieri on the basis of antioxidant, antimicrobial and anti-inflammatory properties. J. Chem. Pharm. Res. 2, 191-198.

Morgan, A., and Stevens, J. (2010). Does bacopa monnieri improve memory performance in older persons? Results of a randomized, placebocontrolled, double-blind trial. J. Altern. Complement. Med. 16, 753-759. doi: 10.1089/acm.2009.0342

Murthy, P. B. S., Raju, V. R., Ramakrisana, T., Chakravarthy, M. S., Kumar, K. V., Kannababu, S., et al. (2006). Estimation of twelve bacopa saponins in bacopa monnieri extracts and formulations by high-performance liquid chromatography. Chem. Pharm. Bull. 54, 907-911. doi: 10.1248/cpb.54.907

Nannepaga, J. S., Korivi, M., Tirumanyam, M., Bommavaram, M., and Kuo, C.-H. (2014). Neuroprotective effects of bacopa monniera whole-plant extract against aluminum-induced hippocampus damage in rats: evidence from electron microscopic images. Chin. J. Physiol. 57, 279-285. doi: 10.4077/CJP.2014.BAC221

Nathan, P., Clarke, J., Lloyd, J., Hutchison, C., Downey, L., and Stough, C. (2001). The acute effects of an extract of bacopa monniera (brahmi) on cognitive function in healthy normal subjects. Hum. Psychopharmacol. Clin. Exp. 16, 345-351. doi: 10.1002/hup.306

Nathan, P. J., Tanner, S., Lloyd, J., Harrison, B., Curran, L., Oliver, C., et al. (2004). Effects of a combined extract of ginkgo biloba and bacopa monniera on cognitive function in healthy humans. Hum. Psychopharmacol. Clin. Exp. 19, 91-96. doi: 10.1002/hup.544

Negi, K., Singh, Y., Kushwaha, K., Rastogi, C., Rathi, A., Srivastava, J., et al. (2000). Clinical evaluation of memory enhancing properties of memory plus in children with attention deficit hyperactivity disorder. Ind. J. Psychiatry 2002:42.

Pandareesh, M., and Anand, T. (2014). Attenuation of smoke induced neuronal and physiological changes by bacoside rich extract in wistar rats via down regulation of ho-1 and inos. Neurotoxicology 40, 33-42. doi: 10.1016/j.neuro.2013.11.001

Pandareesh, M. D., and Anand, T. (2014). Neuroprotective and anti-apoptotic propensity of bacopa monniera extract against sodium nitroprusside induced activation of inos, heat shock proteins and apoptotic markers in pc12 cells. Neurochem. Res. 39, 800-814. doi: 10.1007/s11064-014-1273-7

Pandareesh, M. D., Anand, T., and Bhat, P. V. (2014). Cytoprotective propensity of bacopa monniera against hydrogen peroxide induced oxidative damage in neuronal and lung epithelial cells. Cytotechnology 68, 157-172. doi: 10.1007/ s10616-014-9767-3

Paulose, C., Chathu, F., Khan, S. R., and Krishnakumar, A. (2008). Neuroprotective role of bacopa monnieri extract in epilepsy and effect of glucose supplementation during hypoxia: glutamate receptor gene expression. Neurochem. Res. 33, 1663-1671. doi: 10.1007/s11064-007-9513-8

Peth-Nui, T., Wattanathorn, J., Muchimapura, S., Tong-Un, T., Piyavhatkul, N., Rangseekajee, P., et al. (2012). Effects of 12-week bacopa monnieri consumption on attention, cognitive processing, working memory, and functions of both 
cholinergic and monoaminergic systems in healthy elderly volunteers. Evid. Based Complement. Alternat. Med. 2012:606424. doi: 10.1155/2012/606424

Phrompittayarat, W., Putalun, W., Tanaka, H., Jetiyanon, K., Wittaya-areekul, S., and Ingkaninan, K. (2007). Comparison of various extraction methods of bacopa monnieri. Naresuan Univ. J. 15, 29-34.

Piyabhan, P., and Wetchateng, T. (2013). Cognitive enhancement effects of bacopa monnieri (brahmi) on novel object recognition and vglutl density in the prefrontal cortex, striatum, and hippocampus of sub-chronic phencyclidine rat model of schizophrenia. J. Med. Assoc. Thai. 96, 625-632.

Piyabhan, P., and Wetchateng, T. (2014). Neuroprotective effects of bacopa monnieri (brahmi) on novel object recognition and nmdar1 immunodensity in the prefrontal cortex, striatum and hippocampus of sub-chronic phencyclidine rat model of schizophrenia. J. Med. Assoc. Thai. 97, S50-S55.

Prabhakar, S., Saraf, M. K., Pandhi, P., and Anand, A. (2008). Bacopa monniera exerts antiamnesic effect on diazepam-induced anterograde amnesia in mice. Psychopharmacology 200, 27-37. doi: 10.1007/s00213-007-1049-8

Pravina, K., Ravindra, K. R., Goudar, K. S., Vinod, D. R., Joshua, A. J., Wasim, P., et al. (2007). Safety evaluation of BacoMind ${ }^{\mathrm{TM}}$ in healthy volunteers: a phase I study. Phytomedicine 14, 301-308. doi: 10.1016/j.phymed.2007.03.010

Preethi, J., Singh, H. K., Venkataraman, J. S., and Rajan, K. E. (2014). Standardised extract of bacopa monniera (cdri-08) improves contextual fear memory by differentially regulating the activity of histone acetylation and protein phosphatases (pp1 $\alpha$, pp2a) in hippocampus. Cell. Mol. Neurobiol. 34, 577-589. doi: 10.1007/s10571-014-0042-0

Priyanka, H. P., Singh, R. V., Mishra, M., and ThyagaRajan, S. (2013). Diverse age-related effects of bacopa monnieri and donepezil in vitro on cytokine production, antioxidant enzyme activities, and intracellular targets in splenocytes of $\mathrm{f} 344$ male rats. Int. Immunopharmacol. 15, 260-274. doi: 10.1016/j.intimp.2012.11.018

Rajan, K. E., Singh, H. K., Parkavi, A., and Charles, P. D. (2011). Attenuation of 1-(m-chlorophenyl)biguanide induced hippocampus-dependent memory impairment by a standardised extract of Bacopa monniera (beseb cdri-08). Neurochem. Res. 36, 2136-2144. doi: 10.1007/s11064-011-0538-7

Rao, C. V., Sairam, K., and Goel, R. (2000). Experimental evaluation of bocopa monniera on rat gastric ulceration and secretion. Ind. J. Physiol. Pharmacol. 44, 435-441.

Rashid, S., Lodhi, F., Ahmad, M., and Usmanghani, K. (1990). Cardiovascular effects of bacopa monnieri (1.) pennel extract in rabbits. Pak. J. Pharm. Sci. 3, $57-62$.

Rauf, K., Subhan, F., Abbas, M., Ali, S. M., Ali, G., Ashfaq, M., et al. (2014). Inhibitory effect of bacopasides on spontaneous morphine withdrawal induced depression in mice. Phytother. Res. 28, 937-939. doi: 10.1002/ptr.5081

Rauf, K., Subhan, F., Abbas, M., ul Haq, I., Ali, G., and Ayaz, M. (2012b). Effect of acute and sub chronic use of Bacopa monnieri on dopamine and serotonin turnover in mice whole brain. Afr. J. Pharm. Pharmacol. 6, 2767-2774. doi: 10.5897/AJPP12.244

Rauf, K., Subhan, F., Al-Othman, A., Khan, I., Zarrelli, A., and Shah, M. (2013). Preclinical profile of bacopasides from bacopa monnieri $(\mathrm{bm})$ as an emerging class of therapeutics for management of chronic pains. Curr. Med. Chem. 20, 1028-1037. doi: 10.2174/0929867311320080006

Rauf, K., Subhan, F., and Sewell, R. D. (2012a). A bacoside containing bacopa monnieri extract reduces both morphine hyperactivity plus the elevated striatal dopamine and turnover. Phytother. Res. 26, 758-763. doi: 10.1002/ptr.3631

Reas, S., Amee, K., and Paulose, C. (2008). Glutamate receptor gene expression and binding studies in pilocarpine induced epileptic rat: neuroprotective role of bacopa monnieri extract. Epilep. Behav. 12, 54-60. doi: 10.1016/j.yebeh.2007.09.021

Rehni, A. K., Pantlya, H. S., Shri, R., and Singh, M. (2007). Effect of chlorophyll and aqueous extracts of bacopa monniera and valeriana wallichii on ischaemia and reperfusion-induced cerebral injury in mice. Ind. J. Exp. Biol. 45, 764.

Rohini, G., Sabitha, K., and Devi, C. S. (2004). Bacopa monniera linn. Extract modulates antioxidant and marker enzyme status in fibrosarcoma bearing rats. Ind. J. Exp. Biol. 42, 776-780.

Roodenrys, S., Booth, D., Bulzomi, S., Phipps, A., Micallef, C., and Smoker, J. (2002). Chronic effects of brahmi (bacopa monnieri) on human memory. Neuropsychopharmacology 27, 279-281. doi: 10.1016/S0893-133X(01)00419-5

Sadhu, A., Upadhyay, P., Agrawal, A., Ilango, K., Karmakar, D., Singh, G. P. I., et al. (2014). Management of cognitive determinants in senile dementia of alzheimer's type: therapeutic potential of a novel polyherbal drug product. Clin. Drug Investig. 34, 857-869. doi: 10.1007/s40261-014-0235-9

Sairam, K., Dorababu, M., Goel, R., and Bhattacharya, S. (2002). Antidepressant activity of standardized extract of bacopa monniera in experimental models of depression in rats. Phytomedicine 9, 207-211. doi: 10.1078/0944-711300116

Sairam, K., Rao, C. V., Babu, M. D., and Goel, R. (2001). Prophylactic and curative effects of bacopa monniera in gastric ulcer models. Phytomedicine 8, 423-430. doi: 10.1078/S0944-7113(04)70060-4

Samiulla, D., Prashanth, D., and Amit, A. (2001). Mast cell stabilising activity of bacopa monnieri. Fitoterapia 72, 284-285. doi: 10.1016/S0367-326X(00) 00309-9

Saraf, M. K., Anand, A., and Prabhakar, S. (2010a). Scopolamine induced amnesia is reversed by bacopa monniera through participation of kinase-creb pathway. Neurochem. Res. 35, 279-287. doi: 10.1007/s11064-009-0051-4

Saraf, M. K., Prabhakar, S., and Anand, A. (2010b). Neuroprotective effect of bacopa monniera on ischemia induced brain injury. Pharmacol. Biochem. Behav. 97, 192-197. doi: 10.1016/.j.pbb.2010.07.017

Saraf, M. K., Prabhakar, S., Khanduja, K. L., and Anand, A. (2011). Bacopa monniera attenuates scopolamine-induced impairment of spatial memory in mice. Evid. Based Complement. Alternat. Med. 2011:236186. doi: 10.1093/ecam/ neq038

Saraf, M., Prabhakar, S., and Anand, A. (2009). Bacopa monniera alleviates $\mathrm{n}$ $\omega$-nitro-l-arginine-induced but not mk-801-induced amnesia: a mouse morris water maze study. Neuroscience 160, 149-155. doi: 10.1016/j.neuroscience.2009.02.005

Saraf, M., Prabhakar, S., Pandhi, P., and Anand, A. (2008). Bacopa monniera ameliorates amnesic effects of diazepam qualifying behavioral-molecular partitioning. Neuroscience 155, 476-484. doi: 10.1016/j.neuroscience.2008.05.043

Sharma, R., Chaturvedi, C., and Tewari, P. (1987). Efficacy of bacopa monniera in revitalizing intellectual functions in children. J. Res. Educ. Ind. Med. 1:12.

Shen, Y.-H., Zhou, Y., Zhang, C., Liu, R.-H., Su, J., Liu, X.-H., et al. (2009). Antidepressant effects of methanol extract and fractions of bacopa monnieri. Pharm. Biol. 47, 340-343. doi: 10.1080/13880200902752694

Sheikh, N., Ahmad, A., Siripurapu, K. B., Kuchibhotla, V. K., Singh, S., and Palit, G. (2007). Effect of Bacopa monniera on stress induced changes in plasma corticosterone and brain monoamines in rats. J. Ethnopharmacol. 111, 671-676. doi: 10.1016/j.jep.2007.01.025

Singh, A., and Singh, S. K. (2009). Evaluation of antifertility potential of brahmi in male mouse. Contraception 79, 71-79. doi: 10.1016/j.contraception.2008.07.023

Singh, H., and Dhawan, B. (1982). Effect of bacopa monniera linn.(brâhmi) extract on avoidance responses in rat. J. Ethnopharmacol. 5, 205-214. doi: 10.1016/0378-8741(82)90044-7

Singh, H., and Dhawan, B. (1997). Neuropsychopharmacological effects of the ayurvedic nootropic bacopa monniera linn.(brahmi). Ind. J. Pharmacol. 29, 359.

Singh, R., Ramakrishna, R., Bhateria, M., and Bhatta, R. S. (2014). In vitro evaluation of bacopa monniera extract and individual constituents on human recombinant monoamine oxidase enzymes. Phytother. Res. 28, 1419-1422. doi: $10.1002 /$ ptr.5116

Singh, R. H., and Singh, L. (1980). Studies on the anti-anxiety effect of the medyha rasayana drug, brahmi (bacopa monniera wettst.)-part 1. J. Res. Ayur Siddha 1, $133-148$

Siraj, M., Chakma, N., Rahman, M., Malik, S., and Sadhu, S. (2012). Assessment of analgesic, antidiarrhoeal and cytotoxic activity of ethanolic extract of the whole plant of bacopa monnieri linn. Int. Res. J. Pharm. 3, 98-101. doi: 10.13140/RG. 2.1.3744.9127

Sivaramakrishna, C., Rao, C. V., Trimurtulu, G., Vanisree, M., and Subbaraju, G. V. (2005). Triterpenoid glycosides from bacopa monnieri. Phytochemistry 66, 2719-2728. doi: 10.1016/j.phytochem.2005.09.016

Srivastava, P., Raut, H. N., Puntambekar, H. M., and Desai, A. C. (2012). Stability studies of crude plant material of bacopa monnieri and quantitative determination of bacopaside i and bacoside a by hplc. Phytochem. Anal. 23, 502-507. doi: 10.1002/pca.2347

Stough, C., Lloyd, J., Clarke, J., Downey, L., Hutchison, C., Rodgers, T., et al. (2001). The chronic effects of an extract of bacopa monniera (brahmi) on cognitive function in healthy human subjects. Psychopharmacology 156, 481-484. doi: $10.1007 / \mathrm{s} 002130100815$ 
Stough, C. K., Pase, M. P., Cropley, V., Myers, S., Nolidin, K., King, R., et al. (2012). A randomized controlled trial investigating the effect of Pycnogenol and Bacopa CDRI08 herbal medicines on cognitive, cardiovascular, and biochemical functioning in cognitively healthy elderly people: the Australian Research Council Longevity Intervention (ARCLI) study protocol (ANZCTR12611000487910). Nutr. J. 11:11. doi: 10.1186/1475-2891-11-11

Sumathi, T., and Devaraj, S. N. (2009). Effect of bacopa monniera on liver and kidney toxicity in chronic use of opioids. Phytomedicine 16, 897-903. doi: 10.1016/j.phymed.2009.03.005

Sumathi, T., Nathiya, V., and Sakthikumar, M. (2011). Protective effect of bacosidea against morphine-induced oxidative stress in rats. Ind. J. Pharm. Sci. 73, 409. doi: 10.4103/0250-474X.95624

Velaga, M. K., Basuri, C. K., Robinson Taylor, K. S., Yallapragada, P. R., Rajanna, S., and Rajanna, B. (2013). Ameliorative effects of bacopa monniera on leadinduced oxidative stress in different regions of rat brain. Drug Chem. Toxicol. 37, 357-364. doi: 10.3109/01480545.2013.866137

Verma, P., Singh, P., and Gandhi, B. S. (2014). Neuromodulatory role of bacopa monnieri on oxidative stress induced by postnatal exposure to decabromodiphenyl ether (pbde-209) in neonate and young female mice. Iran. J. Basic Med. Sci. 17, 307.

Viji, V., and Helen, A. (2011). Inhibition of pro-inflammatory mediators: Role of bacopa monniera (1.) wettst. Inflammopharmacology 19, 283-291. doi: 10.1007/s10787-010-0046-4

Vohora, D., Pal, S., and Pillai, K. (2000). Protection from phenytoin-induced cognitive deficit by bacopa monniera, a reputed indian nootropic plant. J. Ethnopharmacol. 71, 383-390. doi: 10.1016/S0378-8741(99)00213-5
Williams, R., Münch, G., Gyengesi, E., and Bennett, L. (2014). Bacopa monnieri (l.) exerts anti-inflammatory effects on cells of the innate immune system in vitro. Food Funct. 5, 517-520. doi: 10.1039/c3fo60467e

Yadav, S., Jain, A., Tripathi, S., and Gupta, J. (1989). Irritable bowel syndrome: therapeutic evaluation of indigenous drugs. Ind. J. Med. Res. 90, 496-503.

Zanotta, D., Puricelli, S., and Bonoldi, G. (2014). Cognitive effects of a dietary supplement made from extract of bacopa monnieri, astaxanthin, phosphatidylserine, and vitamin e in subjects with mild cognitive impairment: a noncomparative, exploratory clinical study. Neuropsychiatr. Dis. Treat. 10, 225-230. doi: 10.2147/NDT.S51092

Zhou, Y., Shen, Y.-H., Zhang, C., Su, J., Liu, R.-H., and Zhang, W.-D. (2007). Triterpene saponins from bacopa monnieri and their antidepressant effects in two mice models. J. Nat. Prod. 70, 652-655. doi: 10.1021/ np060470s

Conflict of Interest Statement: The authors declare that the research was conducted in the absence of any commercial or financial relationships that could be construed as a potential conflict of interest.

Copyright $\odot 2016$ Mathur, Goyal, Koul and Anand. This is an open-access article distributed under the terms of the Creative Commons Attribution License (CC BY). The use, distribution or reproduction in other forums is permitted, provided the original author(s) or licensor are credited and that the original publication in this journal is cited, in accordance with accepted academic practice. No use, distribution or reproduction is permitted which does not comply with these terms. 